\title{
Chronic Total Occlusion Vessel
}

National Cancer Institute

\section{Source}

National Cancer Institute. Chronic Total Occlusion Vessel. NCI Thesaurus. Code C99938.

A longstanding, complete blockage of a vessel. (ACC) 